\title{
Managerial competence as a characteristic of the future officer's personality: experimental results and theoretical conclusions
}

\author{
S.N. Sorokoumova ${ }^{1 *}$, V.N. Buryakov ${ }^{2}$, and D.D. Yarkova ${ }^{3}$ \\ ${ }^{1}$ Russian State Social University, Department of Social and General Psychology, Moscow, Russia \\ ${ }^{2}$ Novosibirsk Military Institute named after General of the Army I.K. Yakovlev of the National Guard \\ of the Russian Federation, Novosibirsk, Russia \\ ${ }^{3}$ Lobachevsky National Research Nizhny Novgorod State University, Nizhny Novgorod, Russia
}

\begin{abstract}
Today, at a time of unstable social, political and economic conditions in Russia and around the world, the importance of opening new ways of development and improving the managerial competence of future officers takes on a special meaning. Today, the requirements for the military profession are changing, for a high level of development of managerial abilities, which are based on managerial competence. The effectiveness of the management activities of future officers in the military directly depends on the level of formation of their managerial competence. The success of the formation of managerial competence of future officers depends on the conditions of the educational environment, which takes into account the social order of society for a fully developed military specialist, optimally integrated into society, able to think outside the box and carry out productive social interactions in various spheres of social and military activities. The novelty of the research consists in the expansion of the conceptual apparatus of pedagogical science by modeling and determining the essence and structure of the managerial competence of the future officer; in the development and experimental testing of a diagnostic device that includes criteria, indicators, evaluation tools, measuring rulers, methods of data interpretation and qualitative characteristics of levels, which allows you to diagnose the levels and indicators of the formation of managerial competence of a future officer.
\end{abstract}

\section{A problem statement}

One of the urgent problems facing modern pedagogical science is the search for ways and means to improve the efficiency of the training process of future officers, the formation of their managerial competence, readiness to solve service and combat tasks in a timely and high-quality manner in any conditions.

The study of the theory and practice of training future officers shows that the process of forming managerial competence in the course of educational activities in military

\footnotetext{
* Corresponding author: prof-ped.gpa@mail.ru
} 
educational institutions of higher education is not always accompanied by high-quality pedagogical support; there are no adequate conditions and programs for its formation, which significantly affects the quality of graduate training.

The word "competence» (competentia) in Latin means a range of issues in which a person is well-informed, has knowledge and experience. A person who is competent in a particular field has the appropriate knowledge and abilities to make informed judgments.

In order to separate the general and individual in the content of competence education, A.V. Khutorskoy [1] distinguishes synonymously used concepts of «competence «and» competence». Competence is a set of interrelated personal qualities (knowledge, skills, skills, methods of activity) that are set in relation to a certain range of subjects and processes and are necessary to act efficiently and productively in relation to them. Competence - the possession, possession of a person of the relevant competence, is including his personal attitude to it and the subject of activity.

\subsection{The objective of the work}

V.I. Baidenko [2], E.V. Bondarevskaya [3], E.A. Gnatyshina [4], E.F. Zeer [5], I.A. Zimnaya [6], N.V. Kuzmina [7], A.K. Markova [8], V.V. Serikov [9], S.N. Sorokoumova [10], E.G. Skibitsky [11], A.V. Khutorsky [12], V.D. Shadrikov [13], A.G. Shabanova [14] et al. The problem of the formation of managerial competence, its essence and development technologies are considered in the previously published works of the author $[15,16]$.

To solve the research problems, the following research methods were used: a) theoretical: analysis, comparison, synthesis, abstraction, modeling; b) empirical: diagnostics, comparative experiment, method, expert assessments, etc.; c) statistical: methods of processing and graphical representation of data, methods for calculating average statistical values, methods for determining the statistical significance of results using the Stadia software package, etc.

\section{Results of the research}

Managerial competence in our opinion, based on the logic of its research, is an integral part of the professional competence of an officer. It is a system of internal resources of the officer-manager necessary for the organization of effective management of the subordinate personnel in any conditions of the situation. It should be considered as a complex system that includes operational and technological, scientific and theoretical, and sociopsychological aspects of management activities.

In our study, managerial competence is characterized by:

- personal traits and attitudes: organization, emotional stability (balance, stress resistance), a tendency to cooperate, confidence (including a representative appearance), energy and endurance);

- professional values: responsibility and commitment, honor of the serviceman, exactingness, professional duty (integrity);

- met competencies: learnability, analyticity, consistency, reflection, concentration;

- professional knowledge in: general and public administration; national and international state structure; national and international politics, economics, demography; world and national history; functional sphere;

- $\quad$ professional skills: goal orientation, ability to analyze the situation and identify the root problem, decision-making, leadership, motivational, organizational skills, presentation skills, negotiator and mediator, mentor, behavioral flexibility, teamwork, efficiency, computer literacy. 
Managerial competence can be defined as an integral quality of the subject of activity, combining motivational-value, worldview, and communication components (abilities, knowledge, skills, etc.) that are significant for its effective implementation, expressed in the characteristics of the observed activity of the subject in the group.

The essence of the managerial competence of the future officer harmoniously integrates professional, pedagogical, psychological, communicative, temporal, legal, economic, human science, organizational, innovative, analytical, strategic, intellectual, psychophysiological and psychotherapeutic components that concretize and enrich its content. The structure of the managerial competence of the future officer, represented by a set of the following components: cognitive, organizational, communicative, reflexive, which perform organizational and executive; planning and predictive; information and analytical; motivational-target and regulatory-correctional functions [15].

In our study, an important stage in achieving the necessary level of managerial competence of a future officer is the stage of identifying pedagogical conditions that contribute to this process.

Based on the definition of conditions that are given in the scientific literature, where the condition expresses the relation of the subject to the surrounding phenomena, without which it cannot exist; the environment in which a particular phenomenon or process arises, exists and develops, it can be concluded that the set of conditions that contribute to a particular phenomenon occurs in a certain educational (pedagogical) environment.

The educational environment is a multi-sphere phenomenon in the totality of the spheres of life of the subjects of education (educational, socio-educational, subject-spatial, personal), determined by the organizational specifics and the spiritual and moral atmosphere of the military institute (way of life, traditions, rituals), the subject-spatial environment (material and technical equipment), the interaction of the cadet and teaching community (event, cooperation, co-creation), the saturation of the content of education (diversity, variability, interactive technologies), the subjective position of the individual (the personal meaning of training), which determine the success of the formation of managerial competence.

The pedagogical conditions for the formation of managerial competence of a future officer include: 1) Activation of cognitive activity of subjects of military education in the "teacher-cadet" system, which is based on the professionalism of teaching staff, their readiness for changing conditions of the educational environment, flexibility of thinking and the desire for constant self-improvement. In the system of pedagogical conditions for the formation of managerial competence of a future officer, it performs the following functions: methodological; epistemological; design; educational. 2) Subject-content structuring of cadet training based on the use of pedagogical technology. Within the framework of understanding this pedagogical condition, we assume the selection of content material structured by goals, topics, tasks and stages, educational and methodological complexes, training modules, etc. types of educational tools. This pedagogical condition in the system of forming the managerial competence of the future officer performs the following functions: informational; informative; training. 3) The presence of the necessary motivation for the development and assimilation of ideas about the competence of the future officer, includes external and internal motives and value-semantic attitudes aimed at the successful performance of service and combat tasks, the leadership position of the officer, his ability to manage the military team. This pedagogical condition in the system of forming the managerial competence of the future officer performs the following functions: value-semantic; orientation; development. 4) The availability of adapted pedagogical support for the formation of managerial competence of the future officer. This pedagogical condition in the system of forming the managerial competence of the future officer performs the following functions: organizational; training; diagnostic; effective [16]. 
Working on the search for ways to improve the managerial competence of future officers, we have identified the following factors that influence this process: pedagogical: this number of factors includes the professional education of pedagogical personnel involved in the process of improving the managerial competence of future officers; technical: providing highly professional equipment, training and education necessary for the organization of the process of improving managerial competence; methodological: these factors include the availability of training programs, methodological complexes, developed manuals and lectures necessary for the organization of improving managerial competence; social: the social conditions of the functioning of an educational institution engaged in improving managerial competence, which will be the necessary basis for the functioning of this process, in addition, it is the ability of the educational institution to organize interaction with other social institutions for better organization of educational activities; socio-cultural: achieving the common goals of all participants in the educational process, developing the cultural traditions of the educational institution.

In order to test the theoretical provisions, we conducted an empirical study of the level of formation of managerial competence, after the introduction of appropriate developments in the pedagogical process. The main objectives of the experiment were to test the effectiveness of the pedagogical conditions identified by us and the developed program for the formation of managerial competence in future officers.

To perform the tasks of the experimental study, we formed a control and experimental group (CG and EG, respectively) from among the cadets of the military institutes of the National Guard troops. The composition of the KG - 146 cadets. the composition of the EG-142 cadets. The control and experimental groups are cadets who were trained in the same course under the educational program «Legal support of national security».

Before conducting the ascertaining stage of the experiment, no additional classes, conversations, etc. were conducted with the cadets in order to form managerial competence.

To determine the level of formation of managerial competence, we have compiled a criterion apparatus, which includes the following blocks:

a) cognitive-reflects the ability to analyze, process, design various alternatives to the use of various data for making managerial decisions;

b) organizational-activity-expresses the ability to organize the necessary data and manage the development of one's own personality, manifests itself in the sphere of personal structures through self-actualization as an indicator of the personal maturity of the subject;

c) communicative-determines the ability of the subject of management relations to influence the performers of management decisions.

The developed criteria apparatus was supposed to evaluate not only the degree of formation of the cadet's managerial competence, but also the organization of his future professional activity. To this end, the experimental work identified the levels of managerial competence formation in the CG and EG (low (not mastering the identified structure of managerial competence of an officer and the inability to implement it in professional and service-combat activities, which corresponds to an assessment of 1-3 points), medium (mastering the identified structure of managerial competence of an officer, but the inability to implement it in professional and service-combat activities, which corresponds to an assessment of 3-6 points), high (full mastery of the identified structure of the officer's managerial competence, the ability to implement it in professional and service-combat activities, which corresponds to an assessment of 6-9 points)) (Table 1, 2, 3). 
Table 1. Results of diagnostics of the level of formation of managerial competence according to the cognitive criterion block in the control group (further $\mathrm{CG}$ ) and the experimental group (further $\mathrm{EG})$ at the ascertaining stage of the experiment $(\mathrm{N}=146.142)$.

\begin{tabular}{|l|l|l|l|l|l|l|}
\hline \multirow{2}{*}{ Groups } & \multicolumn{3}{|c|}{ Low } & \multicolumn{2}{c|}{ Mevels } \\
\cline { 2 - 8 } & \multicolumn{2}{|c|}{ Medium } & \multicolumn{2}{c|}{ High } \\
\hline \multirow{2}{*}{ CG } & Size & $\%$ & Size & $\%$ & Size & $\%$ \\
\cline { 2 - 8 } & 90 & 61.6 & 45 & 30.8 & 11 & 7.5 \\
\hline \multirow{2}{*}{ EG } & Size & $\%$ & Size & $\%$ & Size & $\%$ \\
\cline { 2 - 8 } & 88 & 62 & 44 & 31 & 10 & 7 \\
\hline
\end{tabular}

Table 2. Results of diagnostics of the level of formation of managerial competence according to the organizational-activity criterion block in CG and EG at the ascertaining stage of the experiment $(\mathrm{N}=146.142)$.

\begin{tabular}{|c|c|c|c|c|c|c|}
\hline \multirow[b]{2}{*}{ Groups } & \multicolumn{6}{|c|}{ Levels } \\
\hline & \multicolumn{2}{|c|}{ Low } & \multicolumn{2}{|c|}{ Medium } & \multicolumn{2}{|c|}{ High } \\
\hline \multirow{2}{*}{ CG } & Size & $\%$ & Size & $\%$ & Size & $\%$ \\
\hline & 95 & 65 & 41 & 28 & 10 & 7 \\
\hline \multirow{2}{*}{ EG } & Size & $\%$ & Size & $\%$ & Size & $\%$ \\
\hline & 91 & 64 & 40 & 28.2 & 11 & 7.8 \\
\hline
\end{tabular}

Table 3. Results of diagnostics of the level of formation of managerial competence according to the communicative criterion block in CG and EG at the ascertaining stage of the experiment

$(\mathrm{N}=146.142)$.

\begin{tabular}{|l|l|l|l|l|l|l|}
\hline \multirow{2}{*}{ Groups } & \multicolumn{9}{|c|}{ Levels } \\
\cline { 2 - 8 } & \multicolumn{2}{|c|}{ Low } & \multicolumn{2}{c|}{ Medium } & \multicolumn{2}{c|}{ High } \\
\hline \multirow{2}{*}{ CG } & Size & $\boldsymbol{\%}$ & Size & $\boldsymbol{\%}$ & Size & \% \\
\cline { 2 - 8 } & 93 & 63.7 & 42 & 28.8 & 11 & 7.5 \\
\hline \multirow{2}{*}{ EG } & Size & $\%$ & Size & $\%$ & Size & $\%$ \\
\cline { 2 - 8 } & 92 & 64.8 & 41 & 28.9 & 9 & 6.3 \\
\hline
\end{tabular}

In the third year of the formative experiment, we took into account the shortcomings that occurred during the training of cadets according to the program developed by us and in compliance with the identified pedagogical conditions.

Also, we have worked out the main ways to improve the level of managerial competence of future officers.

The results of the control cross-section according to the criteria blocks of the level of formation of managerial competence developed by us are presented in Table 4-6.

Table 4. Results of diagnostics of the level of formation of managerial competence according to the cognitive criterion block in CG and EG after the third year $(\mathrm{N}=146.142)$.

\begin{tabular}{|c|l|l|l|l|l|l|}
\hline \multirow{2}{*}{ Groups } & \multicolumn{4}{|c|}{ Low } & \multicolumn{2}{c|}{ Mevels } \\
\cline { 2 - 8 } & \multicolumn{2}{|c|}{ Medium } & \multicolumn{2}{c|}{ High } \\
\hline \multirow{2}{*}{ CG } & Size & $\%$ & Size & $\%$ & Size & $\%$ \\
\cline { 2 - 8 } & 76 & 52 & 54 & 37 & 16 & 11 \\
\hline \multirow{2}{*}{ EG } & Size & $\%$ & Size & $\%$ & Size & $\%$ \\
\hline
\end{tabular}


Table 5. Results of diagnostics of the level of formation of managerial competence according to the organizational and activity criteria block in $\mathrm{KG}$ and $\mathrm{EG}$ after the third year $(\mathrm{N}=146.142)$.

\begin{tabular}{|c|l|l|l|l|l|l|}
\hline \multirow{2}{*}{ Groups } & \multicolumn{6}{|c|}{ Levels } \\
\cline { 2 - 8 } & \multicolumn{2}{|c|}{ Low } & \multicolumn{2}{c|}{ Medium } & \multicolumn{2}{c|}{ High } \\
\hline \multirow{2}{*}{ CG } & Size & $\boldsymbol{\%}$ & Size & $\boldsymbol{\%}$ & Size & $\%$ \\
\cline { 2 - 8 } & 75 & 51.4 & 53 & 36.3 & 18 & 12.3 \\
\hline EG & Size & $\%$ & Size & $\%$ & Size & $\%$ \\
\hline
\end{tabular}

Table 6. Results of diagnostics of the level of formation of managerial competence according to the communicative criterion block in CG and EG after the third year $(\mathrm{N}=146,142)$.

\begin{tabular}{|c|l|l|l|l|l|l|}
\hline \multirow{2}{*}{ Groups } & \multicolumn{6}{|c|}{ Levels } \\
\cline { 2 - 8 } & \multicolumn{3}{|c|}{ Low } & Medium & High \\
\hline \multirow{2}{*}{ CG } & Size & $\%$ & Size & \% & Size & \% \\
\cline { 2 - 8 } & 74 & 50.7 & 55 & 37.7 & 17 & 11.6 \\
\hline \multirow{2}{*}{ EG } & Size & $\%$ & Size & \% & Size & \% \\
\cline { 2 - 8 } & 24 & 16.9 & 82 & 57.8 & 36 & 25.4 \\
\hline
\end{tabular}

In order to determine the dependence of the obtained values on the introduction of author's developments into the pedagogical process of the military institute and the identified pedagogical conditions, we applied the X2 consent criterion (Table 7).

Table 7. Calculation of the chi-square for the change in the level of formation of managerial competence after the third year of the formative experiment.

\begin{tabular}{|l|l|l|l|l|}
\hline \multicolumn{1}{|c|}{$\mathbf{f}_{\mathbf{0}}$} & \multicolumn{1}{c|}{$\mathbf{f}_{\mathbf{e}}$} & \multicolumn{1}{c|}{$\mathbf{f}_{\mathbf{0}}-\mathbf{f}_{\mathbf{e}}$} & \multicolumn{1}{c|}{$\left(\mathbf{f}_{\mathbf{0}}-\mathbf{f}_{\mathbf{e}}\right)^{\mathbf{2}}$} & \multicolumn{1}{c|}{$\left(\mathbf{f}_{\mathbf{0}}-\mathbf{f}_{\mathbf{e}}\right)^{\mathbf{2}} / \mathbf{f}_{\mathbf{e}}$} \\
\hline 52 & 26.8 & 25.1 & 630.01 & 23.5 \\
\hline 37 & 52.8 & -15.8 & 249.64 & 4.73 \\
\hline 11 & 20.4 & -9.4 & 88.36 & 4.33 \\
\hline 26,8 & 20.4 & 6.4 & 40.96 & 2.01 \\
\hline 52,8 & 57 & $-4,2$ & 17.64 & 0.31 \\
\hline 20,4 & 22.6 & -2.2 & 5.28 & 0.23 \\
\hline 50,7 & 16.9 & 33.8 & 1142.44 & 50.55 \\
\hline 37,7 & 57.8 & -20.1 & 404.01 & 6.99 \\
\hline 11,6 & 25.4 & -13.8 & 190.44 & 7.5 \\
\hline
\end{tabular}

$X^{2}=100.15$

$D(f)=(r-1)(c-1)=(9-1)(3-1)=8 * 2=16$

$\mathrm{X}$-square $=100.15$ at $\mathrm{D}(\mathrm{f})=16$ (according to Table. 7 ) greater than 16 , therefore, the data is significant.

\section{Conclusions}

Thus, the experimental results obtained and their statistical processing confirm the effectiveness of the work carried out. Of particular importance in the process of improving the level of managerial competence is the interaction of the teacher and the cadet. The teacher acts as an active subject of the educational process, advising, coordinating the head and expert of education for the cadet. The teaching staff is obliged to follow the principles 
of dynamic, reflexive and open to all forms of interaction activities, to encourage and encourage independence among cadets.

The cadet in the studied process acts as a student who has a clear active-search creative position in training, has positive motives and an improving value-semantic system aimed at the qualitative assimilation of the training program with the proposed elements of the formation of managerial competence. Pedagogical support of the process of improving the level of managerial competence of cadets is a necessary protective shell, carried out in order to coordinate, direct the process and consolidate the results obtained.

\section{References}

1. A.V. Khutorskoy, Key competencies: construction technology, Narodnoe obrazovanie, 5, 11-18 (2003)

2. V.I. Baidenko, Competences in professional education, Higher education in Russia, 11, 3-13 (2004)

3. E.V. Bondarevskaya, Paradigmal approach to the development of the content of key pedagogical competencies, Pedagogika, 10, 23-31 (2004)

4. E.A. Gnatyshina, Competence-oriented management of training of teachers of professional training, 424 (2008)

5. E.F. Zeer, Competence approach to the modernization of professional education, Higher education in Russia, 4, 23-30 (2005)

6. I.A. Zimnaya, Key competencies as a performance-target basis of the competence approach in education, 40 (2004)

7. A.K. Markova, Psychology of professionalism, 308 (1996)

8. G.A. Sergeev, Competence and competences in education, 144 (2010)

9. V.V. Serikov, Competence model: from an idea to an educational program, Pedagogika, 10, 8-14 (2003)

10. P.A. Egorova et al., Development of key personal competencies of future officers of the internal troops of the Ministry of Internal Affairs of Russia, Pedagogy and Psychology of Education, 4, 44-56 (2015)

11. E.G. Skibitsky, Pedagogy of higher school, 388 (2013)

12. A.V. Khutorskoy, Key competencies as a component of the personality-oriented paradigm of education, Narodnoe obrazovanie, 2, 32-41 (2003)

13. V.D. Shadrikov, A new model of a specialist: innovative training and competence approach, Higher education today, 8, 26-31 (2004)

14. A.G. Shabanov, Construction of the information and educational environment of the university as the main condition for the implementation of the competence approach in higher education, Trudy SGA, 12, 72-83 (2011)

15. V.N. Buryakov, The essence of managerial competence of future officers of the internal troops of the Ministry of Internal Affairs of Russia, Modern studies of social problems (Electronic Scientific Journal), 11(55), 739-746 (2015)

16. V.N. Buryakov, Pedagogical technology of formation of managerial competence of future officers, Sovremennye issledovaniya sotsialnykh problemy (Electronic scientific journal), 11(55), 747-759 (2015) 